Check for updates

Cite this: RSC Adv., 2017, 7, 20840

Received 22nd January 2017

Accepted 29th March 2017

DOI: 10.1039/c7ra00851a

rsc.li/rsc-advances

\section{Unusual crystal structure and chirality of uridine 5'-monophosphate coordination polymer $\dagger$}

\begin{abstract}
Leilei Gu, ${ }^{a}$ Qi-ming Qiu, ${ }^{a}$ Pei Zhou, ${ }^{a}$ Liang Hao, ${ }^{a}$ Minghua Liu (D) ${ }^{b}$ and Hui Li (D)*a
Two types of $\mathrm{Cu}(\|)-U M P-L$ coordination polymers, $\left\{\left[\mathrm{Cu}_{2}(\mathrm{UMP})_{2}(\mathrm{bpda})_{2}\left(\mathrm{H}_{2} \mathrm{O}\right)_{3}\right] \cdot 10 \mathrm{H}_{2} \mathrm{O}\right\}_{n}$ (1) and $\left\{\left[\mathrm{Cu}_{2}(\mathrm{UMP})_{2}(\mathrm{bpe})_{2}\left(\mathrm{H}_{2} \mathrm{O}\right)_{2}\right] \cdot 7 \mathrm{H}_{2} \mathrm{O}\right\}_{n}$ (2) (UMP = uridine $5^{\prime}$-monophosphate, bpda = 1,4-bis(4-pyridyl)-2,3diaza-1,3-butadiene, bpe =1,2-bis(4-pyridyl)ethylene), were designed and synthesized for researching the effect of auxiliary ligand. X-ray single-crystal diffraction analysis revealed that complex 1 is the first example of a 1D parallel double-bridged coordination polymer in a nucleotide-metal coordination complex, while complex 2 is a 2D grid coordination polymer. Based on their crystal structure analysis, their chirality, including molecular chirality, supramolecular helical chirality and auxiliary ligand's extended axial chirality (EAC), was studied by aqueous solution and solid state circular dichroism (CD) spectroscopy. The length and conjugated auxiliary ligand had an influence on the EAC.
\end{abstract}

\section{Introduction}

Metal-nucleotide coordination complexes are important both in chemistry and biology domains. ${ }^{1}$ These bio-coordination polymers are appealing as templates to mediate the synthesis of inorganic nanoparticles (NPs), ${ }^{2}$ accumulating heavy metal and rare earth ions in aqueous solution, ${ }^{3}$ drug delivery, ${ }^{4}$ regulating enzyme function in cell $^{5}$ and switching hierarchical levels in biological systems. ${ }^{6}$ The complexes of adenosine, cytidine, guanosine and thymidine, uridine phosphates are the five most important nucleotide complexes found in living organisms, in which the metal-binding modes for various nucleotides are different. ${ }^{7-9}$ For the purine base nucleotides, N7 and O donor of the base motif actively coordinate with metal ions. ${ }^{\mathbf{1 0 - 1 2}}$ In contrast, uridine and its analogues are the least active nucleosides, since the N3 of uridine (Scheme 1) can be a potential donor only when it is deprotonated at $\mathrm{pH}>9$, and usually carbonyl of uridine is not active. ${ }^{\mathbf{1 1}}$ The coordinating functional group of UMP to metal ions is actually a phosphate group. ${ }^{13}$ The coordinating ability of nucleotides changes in the following order: GMP > IMP > AMP > CMP $=$ UMP. ${ }^{\mathbf{1 4}}$ Therefore, the structurally elucidated UMP coordination complexes are very rare. ${ }^{15,16}$ Recently, we reported the ternary assembly of a UMP coordination complex, $\left\{\mathrm{Ni}(\mathrm{UMP})\left(4,4^{\prime}\right.\right.$-bipy $\left.\left.)\left(\mathrm{H}_{2} \mathrm{O}\right)_{3}\right] \cdot \mathrm{H}_{2} \mathrm{O}\right\}_{n}$, and

${ }^{a}$ Key Laboratory of Clusters Science of Ministry of Education, School of Chemistry and Chemical Engineering, Beijing Institute of Technology, Beijing 100081, P. R. China. E-mail: lihui@bit.edu.cn; Fax: +86-10-68914780-804; Tel: +86-10-68912667

${ }^{b}$ National Center for Nanoscience and Technology, Beijing 100190, P. R. China. E-mail: liumh@iccas.ac.cn

$\dagger$ Electronic supplementary information (ESI) available: Structure information, spectra (IR, UV-vis and CD), ESI-MS, XRD and crystallographic data (CIF). CCDC 1487536 and 1509043. For ESI and crystallographic data in CIF or other electronic format see DOI: $10.1039 / \mathrm{c} 7 \mathrm{ra00851a}$ proposed the extended axial chirality (EAC) for the first time. ${ }^{\mathbf{1 6}}$ The concept relates the axial chirality in organic chemistry to coordination polymers, which describes a chiral conformation of coordination polymer generated by bridge ligands with a limited rotation of aryl-aryl single bonds through coordination interaction and intermolecular interaction with nucleotides, and the symmetry is broken after the extension. Due to the chiral inducer surrounding the axis of auxiliary ligand clockwise, the absolute axial chiral configuration of the auxiliary ligand is $P$, otherwise is $M$ configuration. In previous study, several types of bipyridyl-based bridge ligands were used to successfully tune the chirality and structure of the complexes. ${ }^{\mathbf{1 6 - 1 8}}$

In this study, 1,2-bis(4-pyridyl)ethylene (bpe) and 1,4-bis(4pyridyl)-2,3-diaza-1,3-butadiene (bpda) were chosen to study the length and conjugation of the auxiliary ligand in the structure and chirality of the ternary assembly (Scheme 1). The linker of the two bridge ligands was different, in which bpda with a longer spacer $-\mathrm{C}=\mathrm{N}-\mathrm{N}=\mathrm{C}$ - is a stronger Lewis base $\left(\mathrm{p} K_{\mathrm{b}}=8.81\right)$ than that of bpe with $-\mathrm{C}=\mathrm{C}-\left(\mathrm{p} K_{\mathrm{b}}=9.32\right) .{ }^{19,20}$ Their electronic structures were also different and resulted in different $\pi$-stacking interactions. ${ }^{21,22}$ Herein, 1D double-bridged $\left\{\left[\mathrm{Cu}_{2}(\mathrm{UMP})_{2}(\mathrm{bpda})_{2}\left(\mathrm{H}_{2} \mathrm{O}\right)_{3}\right] \cdot 10 \mathrm{H}_{2} \mathrm{O}\right\}_{n}$ (1) and 2D sheet $\left\{\left[\mathrm{Cu}_{2}(\mathrm{UMP})_{2}(\mathrm{bpe})_{2}\left(\mathrm{H}_{2} \mathrm{O}\right)_{2} \cdot 7 \mathrm{H}_{2} \mathrm{O}\right]\right\}_{n}$ (2) were obtained and characterized by X-ray single crystal diffraction. To the

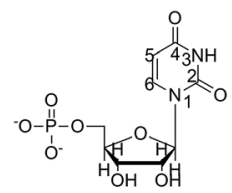

UMP

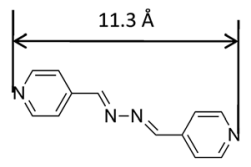

bpda

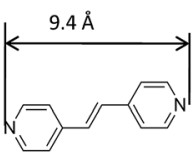

bpe
Scheme 1 Molecular structures of UMP, bpda and bpe. 
best of our knowledge, complex 1 is the first 1D coordinated polymer with double bpda bridges. The chirality was studied based on single crystal structure analysis as well as solution and solid state circular dichroism (CD) spectroscopy.

\section{Experimental}

\section{Materials and methods}

With the exception of the ligands, bpda was prepared according to a literature procedure, ${ }^{19}$ and all reagents and solvents for the synthesis and analysis were commercially available and used as received without further purification. FT-IR spectra were recorded on a Nicolet-360 FT-IR spectrometer with $\mathrm{KBr}$ pellets in the 4000$400 \mathrm{~cm}^{-1}$ region. Elemental analyses $(\mathrm{C}, \mathrm{H}, \mathrm{N})$ were recorded on a EA3000 elemental analyzer at the Beijing Institute of Technology. Thermo-gravimetric analyses (TGA) were performed on a DTG-60H thermal analyzer from room temperature to $800{ }^{\circ} \mathrm{C}$ with a heating rate of $10^{\circ} \mathrm{C} \mathrm{min}{ }^{-1}$ in a flowing $50 \mathrm{~mL} \mathrm{~min}{ }^{-1}$ nitrogen atmosphere. UV-vis spectra were obtained on a TU-1950 spectrophotometer. Powder X-ray diffraction (PXRD) studies of samples were carried out using a Japan Rigaku D/max $\gamma$ A X-ray diffractometer measured with graphite-monochromatized Mo $K \alpha$ radiation $(\lambda=0.71073 \AA)$. CD measurements were performed at $25{ }^{\circ} \mathrm{C}$ under a constant nitrogen flow on a JASCO J-810 spectropolarimeter. For solid-state (CD) measurement of UMP ligand and complexes $\mathbf{1}$ and 2, the ratio of crystalline sample and $\mathrm{KCl}$ powder was $1: 200$, and the mixture was pressed into a disk by a literature method. ${ }^{23}$

$\left\{\left[\mathrm{Cu}_{2}(\mathrm{UMP})_{2}(\mathrm{bpda})_{2}\left(\mathrm{H}_{2} \mathrm{O}\right)_{3}\right] \cdot \mathbf{1 0 H}_{2} \mathbf{O}\right\}_{n}$ (1). An aqueous solution $(2.5 \mathrm{~mL})$ of $\mathrm{Na}_{2} \mathrm{UMP}(18 \mathrm{mg}, 0.05 \mathrm{mmol})$ was added into an aqueous solution $(2.5 \mathrm{~mL})$ of $\mathrm{Cu}\left(\mathrm{NO}_{3}\right)_{2} \cdot 3 \mathrm{H}_{2} \mathrm{O}(12 \mathrm{mg}, 0.05$ mmol) with stirring. Then, an ethanol solution $(5 \mathrm{~mL})$ of bpda (10 $\mathrm{mg}, 0.05 \mathrm{mmol}$ ) was added to this mixture after $30 \mathrm{~min}$. The suspension acidity was adjusted by $\mathrm{HNO}_{3}(1 \mathrm{M})$ until the solution became clear $(\mathrm{pH}=4-5)$. The mixture was stirred at room temperature for $30 \mathrm{~min}$ and filtered. Blue single crystals suitable for X-ray diffraction analysis were obtained after one month by evaporating under room temperature. The yield was $68 \%$. Anal. Calc. (\%) for $\mathrm{C}_{42} \mathrm{H}_{68} \mathrm{Cu}_{2} \mathrm{~N}_{12} \mathrm{O}_{31} \mathrm{P}_{2}\left(M_{\mathrm{r}}=1426.10\right): \mathrm{C}, 35.37 ; \mathrm{H}$, 4.80; N, 11.78. Found (\%): C, 34.93; H, 4.88; N, 11.52. Selected IR $\left(\mathrm{KBr}, \mathrm{cm}^{-1}\right): 3424 \mathrm{~s}, 1681 \mathrm{~s}, 1615 \mathrm{~s}, 1422 \mathrm{~s}, 1236 \mathrm{~m}, 1112 \mathrm{~m}$, 1060 s, 992 s, 823 m, 694 m, 529 m (Fig. S1a †).

$\left\{\left[\mathrm{Cu}_{2}(\mathrm{UMP})_{2}(\mathbf{b p e})_{2}\left(\mathbf{H}_{2} \mathbf{O}\right)_{2}\right] \cdot 7 \mathbf{H}_{2} \mathbf{O}\right\}_{n}$ (2). The same experimental conditions used for 1 were adopted, except that bpda was replaced by bpe ( $9 \mathrm{mg}, 0.05 \mathrm{mmol})$. The blue hexagon bulk single crystals suitable for X-ray diffraction were obtained by evaporating the solvent at room temperature over a week. The yield was $63 \%$. Anal. calc. (\%) for $\mathrm{C}_{42} \mathrm{H}_{58} \mathrm{Cu}_{2} \mathrm{~N}_{8} \mathrm{O}_{27} \mathrm{P}_{2}\left(M_{\mathrm{r}}=\right.$ 1295.98): C, 38.92; H, 4.51; N, 8.64. Found (\%): C, 38.79; H, 4.53; $\mathrm{N}, 8.73$. Selected IR $\left(\mathrm{KBr}, \mathrm{cm}^{-1}\right): 3355 \mathrm{~s}, 1648 \mathrm{~s}, 1604 \mathrm{~s}, 1535 \mathrm{w}$, $1486 \mathrm{~m}, 1428 \mathrm{~m}, 1408 \mathrm{~m}, 1339 \mathrm{~m}, 1300 \mathrm{~m}, 1249 \mathrm{w}, 1218 \mathrm{~s}, 1090$ vs., 975 s, 936 m, 904 m, 819 m, 797w, 728 m, 632 m (Fig. S1b†).

\section{Single crystal X-ray diffraction}

X-ray single-crystal diffraction data for complexes $\mathbf{1}$ and $\mathbf{2}$ were collected on a Bruker AXS CCD area detector with graphite
Table 1 Crystallographic parameters for complexes 1 and 2

\begin{tabular}{lll}
\hline Complex & $\mathbf{1}$ & 2 \\
\hline Formula & $\mathrm{C}_{42} \mathrm{H}_{68} \mathrm{Cu}_{2} \mathrm{~N}_{12} \mathrm{O}_{31} \mathrm{P}_{2}$ & $\mathrm{C}_{42} \mathrm{H}_{58} \mathrm{Cu}_{2} \mathrm{~N}_{8} \mathrm{O}_{27} \mathrm{P}_{2}$ \\
$M_{\mathrm{r}}$ & 1426.10 & 1295.98 \\
Temperature (K) & $296(2)$ & $153(2)$ \\
Crystal system & Monoclinic & Monoclinic \\
Space group & $P 2_{1}$ & $C 2$ \\
$a(\AA)$ & $10.364(3)$ & $30.261(6)$ \\
$b(\AA)$ & $20.041(6)$ & $9.6957(19)$ \\
$c(\AA)$ & $15.393(4)$ & $21.350(4)$ \\
$\alpha\left({ }^{\circ}\right)$ & 90 & 90 \\
$\beta\left({ }^{\circ}\right)$ & $98.080(7)$ & $120.61(3)$ \\
$\gamma\left({ }^{\circ}\right)$ & 90 & 90 \\
$V\left(\AA^{3}\right)$ & $3165.2(14)$ & $5391(2)$ \\
$Z$ & 2 & 4 \\
$F(000)$ & 1480 & 2680 \\
Reflections collected & 27649 & 24399 \\
Independent reflections & 11171 & 13881 \\
Goodness-of-fit on $F^{2}$ & 1.046 & 1.045 \\
$R_{\text {int }}$ & 0.0909 & 0.0357 \\
$R_{1}[I>2 \sigma(I)]$ & 0.0710 & 0.0732 \\
$\mathrm{w} R_{2}[I>2 \sigma(I)]$ & 0.1672 & 0.1934 \\
$R_{1}($ all data) & 0.1104 & 0.0838 \\
$\mathrm{w} R_{2}($ all data) & 0.1815 & 0.2043 \\
Flack parameter & $0.038(11)$ & $0.053(7)$ \\
& &
\end{tabular}

monochromatic molybdenum $\mathrm{K} \alpha(\lambda=0.71073 \AA)$ radiation. Unit-cell parameters were determined from automatic centering and were refined by the least-squares method. The structure was solved by direct methods and refined using fullmatrix least-square techniques on $F^{2}$ with the SHELXTL program. ${ }^{24}$ All non-hydrogen atomic positions were located by a full-matrix least-squares method and refined anisotropically. Hydrogen atoms in water were placed in their geometrically generated positions and other hydrogen atoms bonded with carbon or nitrogen were located from different Fourier maps and refined isotropically. The crystallographic data and refinement parameters are presented in Table 1, and H-bonding and selected bond lengths and angles are summarized in Tables S2S5 in the ESI. $\dagger$ CCDC-1487536 (1), 1509043 (2) contain the supplementary crystallographic data for this study.

\section{Results and discussion}

\section{Auxiliary ligand and $\mathrm{Cu}-\mathrm{UMP}$ binding}

From previous studies, the coordination ratio of the auxiliary ligand going from binary to ternary in the solution could be studied by UV titration. ${ }^{25-28}$ In order to study the interactions of bpda/bpe with $\mathrm{Cu}-\mathrm{UMP}$ in an aqueous medium, UV titrations were carried out by adding an auxiliary ligand to the solution of $\mathrm{Cu}$-UMP. UV absorbance was measured as a function of concentration of bpda and bpe (Fig. S2 and Table S1†). With increased auxiliary ligand content the apparent intensity increased at 250-300 $\mathrm{nm}$, and broadened the main absorption at $265 \mathrm{~nm}$; this was due to the strong intermolecular interaction for the strong $\pi-\pi^{*}$ transition. A blue shift at $200-225 \mathrm{~nm}$ occurred, which was related to the $\mathrm{n}-\pi^{*}$ transitions of the complex. The isosbestic point around $223 \mathrm{~nm}$ indicated that 

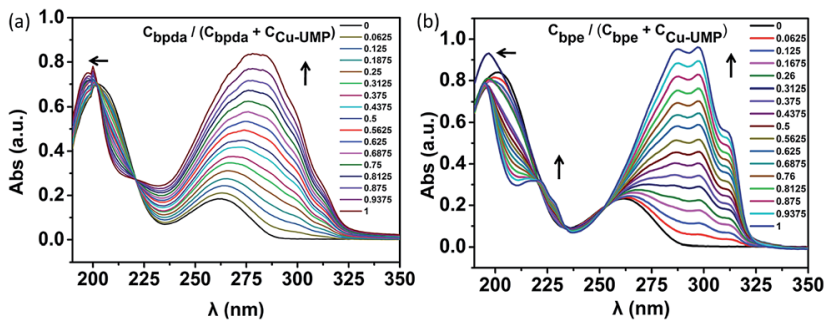

Fig. 1 Electronic spectra of Cu-UMP (1:1) upon addition of (a) bpda (b) bpe. The total concentration of $\mathrm{Cu}$-UMP and bpda/bpe is held fixed $\left(3.0 \times 10^{-5} \mathrm{M}\right)$ and varying the ratio of the components $\left(C_{\text {bpda }} / C_{\text {Cu-Ump }}\right.$ and $\left.C_{\text {bpe }} / C_{\text {Cu-UMP }}\right)$.

a new complex was generated in the solution. Moreover, after the ratio of $C_{\text {ligand }} / C_{\mathrm{Cu}-\mathrm{UMP}}=0.5$, the main absorption was maintained at $280 / 293 \mathrm{~nm}$, which illustrated ternary formations at an equimolar concentration of bpda/bpe and $\mathrm{Cu}-\mathrm{UMP}$ (Fig. 1). After each addition of bpda/bpe, the difference $\Delta \lambda\left(\lambda_{\max }\right.$ $\left.-\lambda_{\text {iso }}\right)$ was obtained as a function of $C_{\text {ligand }} /\left(C_{\mathrm{Cu}-\mathrm{UMP}}+C_{\text {ligand }}\right)$. The plots show that the complex was $1: 1$ adduct; this further confirms that the ternary assembly was a $1: 1: 1$ assembly in the solution (Fig. S3†).

\section{Structure description}

$\left\{\left[\mathrm{Cu}_{2}(\mathrm{UMP})_{2}(\text { bpda })_{2}\left(\mathrm{H}_{2} \mathrm{O}\right)_{3}\right] \cdot \mathbf{1 0 H}_{2} \mathrm{O}\right\}_{n}(\mathbf{1})$. X-ray single crystal diffraction revealed that complex 1 is a $1 \mathrm{D}$ double-chain coordination polymer constructed by a double-bridge of bpda, which crystallized in the monoclinic $P 2_{1}$ chiral space group (Table 1), which indicated that the crystal is homochiral. In the asymmetry unit, there are two $\mathrm{Cu}(\mathrm{II})$ ions, which are both fivecoordinated with a square-pyramidal geometry that include bridging phosphate of UMP, bpda and coordinated water molecule.

However, the coordination spheres of $\mathrm{Cu} 1$ and $\mathrm{Cu} 2$ are different, in which the remaining coordination position of $\mathrm{Cu} 1$ was occupied by a water molecule, while $\mathrm{Cu} 2$ was occupied by a terminal UMP ligand (Fig. 2a). Bond distances for $\mathrm{Cu}-\mathrm{O}$ (1.942(6) $\AA$ ) and $\mathrm{Cu}-\mathrm{N}(2.035(7) \AA)$ are close to the mean value found for square pyramidal $\mathrm{Cu}(\mathrm{II})$ complexes $(1.970(2) \AA$, 2.025(3) A). ${ }^{16}$ The building block for a 1D coordination polymer is a dinuclear $\mathrm{Cu}$ (II) unit linked by UMP $(\mathrm{Cu} \cdots \mathrm{Cu}$ : $3.940(2) \AA)$, in which each $\mathrm{Cu}(\mathrm{II})$ is bridged by a bpda ligand to extend the $1 \mathrm{D}$ polymer, which exhibits an unusual double-bridge 1D structure (Fig. 2b). The distance between the two planar bpda ligands within the chain is 3.756(9) $\AA$ with a $\pi-\pi$ stacking interaction. The width of the $1 \mathrm{D}$ belt-type coordination polymer is 14.350(13) A (Fig. S4 $\dagger$ ). The orientation of the UMP nucleobases of UMP is parallel with the bpda ligand induced by the intrachain $\pi-\pi$ interactions between the nucleobase and bpda (3.808(9) A and 3.579(9) §). This type of UMP orientation relative to the $1 \mathrm{D}$ chain leads to the $\mathrm{Cu} \cdots \mathrm{Cu}$ distance of the neighboring belt being 6.779(2) $\AA$ and prohibits the bridging function of $\mathrm{PO}_{4}$ group of UMP along the 2D direction. As in our previous study, the similar orientation of nucleobases also leads to a $1 \mathrm{D}$ coordination polymer in the CMP-bpe-Co complex and not a $2 \mathrm{D}$ (a)

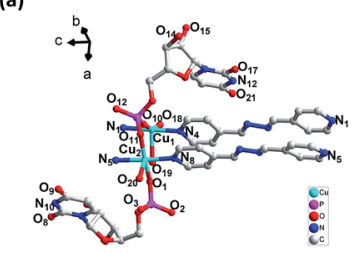

(b)

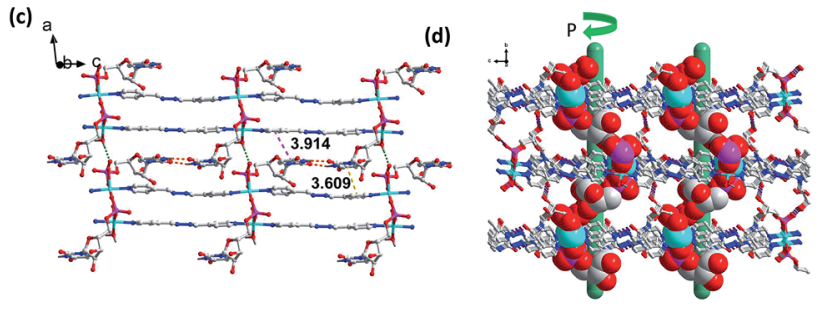

Fig. 2 (a) The asymmetric unit of complex 1 . The solvent molecules and hydrogen atoms are not shown for clarity. (b) 1D chain of complex 1 viewed down from the $b$ axis. (c) 2D layer based on inter-chain $\mathrm{H}$ -

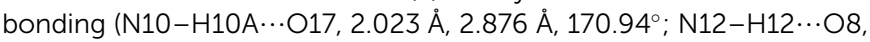
$1.935 \AA, 2.782 \AA, 168.33^{\circ}$ ) and $\pi-\pi$ interactions. (d) $3 D$ supramolecular framework based on $\mathrm{H}$-bonding $(\mathrm{O} 6-\mathrm{H} 6 \cdots \mathrm{O} 12,1.891 \AA$, $2.687 \AA$,

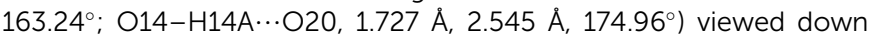
from the a-axis and $P$ helix formed by $\mathrm{H}$-bonding $(\mathrm{O} 6-\mathrm{H} 6 \cdots \mathrm{O} 12,1.891$ $\AA$, $2.687 \AA, 163.24^{\circ}$ ).

coordination polymer. ${ }^{30}$ The key interactions between the $1 \mathrm{D}$ chains are the base-pair H-bonding (N10-H10A ‥ $117,2.023 \AA$,

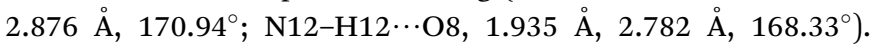
Moreover, there are inter-chain $\pi-\pi$ stacking interactions produced by the nucleobases with the bpda ligand (3.609(1) $\AA$ and 3.914(9) $\AA$ ) (Fig. 2c and S5 $\dagger$ ). In addition, H-bonding formed by the coordinated oxygen atom of water with the phosphate

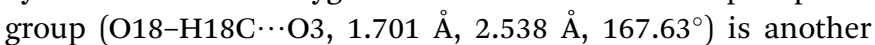
force to assemble the $1 \mathrm{D}$ chains into a $2 \mathrm{D}$ sheet (Fig. $2 \mathrm{c}$ and $\mathrm{S} 5 \dagger$ ). The $2 \mathrm{D}$ sheets can be further organized into a 3D supramolecular framework through $\mathrm{H}$-bonding (O6-H6 $\cdots \mathrm{O} 12,1.891$

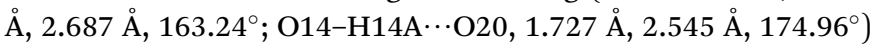
between hydroxyl group of pentose and oxygen of phosphate group as well as hydroxyl group of pentose and coordinated water (Fig. S5 $\dagger$ ). There is helical H-bonding formed by the hydroxyl group of pentose with the oxygen of phosphate group

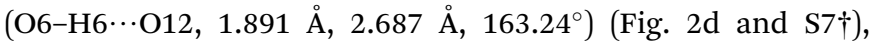
which is a $P$ helix with a screw pitch of 20.0(1) A.

$\left\{\left[\mathrm{Cu}_{2}(\mathrm{UMP})_{2}(\mathrm{bpe})_{2}\left(\mathbf{H}_{2} \mathbf{O}\right)_{2}\right] \cdot 7 \mathbf{H}_{2} \mathbf{O}\right\}_{n}$ (2). The crystal structure of 2 is a $2 \mathrm{D}$ coordination polymer (Fig. 3 ) that crystallizes in the monoclinic $C 2$ space group, which indicates that the crystal is homochiral. All the $\mathrm{Cu}$ (II) ions were five coordinated with two bridging phosphate oxygens, two bpe nitrogens, and one water oxygen, which presented the $\mathrm{CuN}_{2} \mathrm{O}_{3}$ distorted square pyramidal structure (Fig. 3a). The $\mathrm{Cu}(\mathrm{II})-\mathrm{N}$ and $\mathrm{Cu}(\mathrm{II})-\mathrm{O}$ distances were similar to that of complex 1 , which was normal $\mathrm{Cu}(\mathrm{II})-\mathrm{N}$ and $\mathrm{Cu}(\mathrm{II})-\mathrm{O}$ coordination bonding. ${ }^{28}$ Only the distances of $\mathrm{Cu}(\mathrm{II})-\mathrm{O}_{\text {water }}(2.299(6) \AA)$ and $\mathrm{Cu}(2)-\mathrm{O}(22)(2.324(13) \AA)$ were longer than the normal $\mathrm{Cu}(\mathrm{II})-\mathrm{O}$ length, which was caused by the Jahn-Teller effect. $^{29}$ UMP and bpe act as the bridging ligands that connect the $\mathrm{Cu}(\mathrm{II})$ ions into a $2 \mathrm{D}$ grid with corresponding distances of 5.057(1) Å and 5.115(1) ̊, 13.437(6) A and 13.442(6) $\AA$ (Fig. S8†). In contrast with complex 1, due to the 


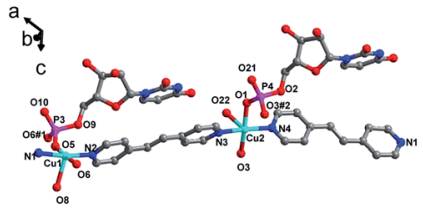

(b)

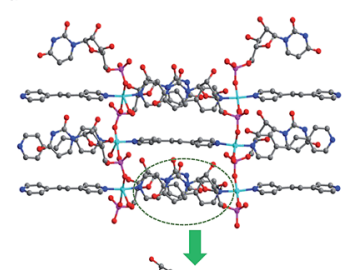

(c)
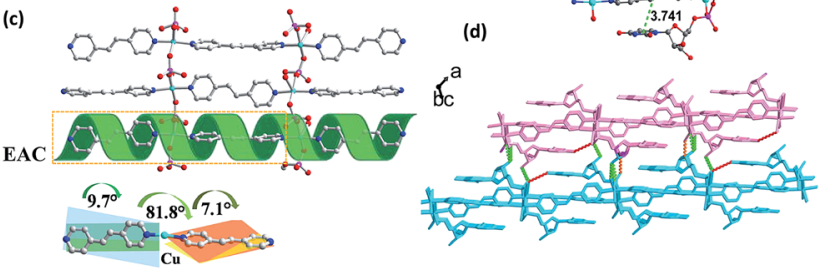

Fig. 3 (a) The asymmetric unit of complex 2. The solvent molecules and hydrogen atoms are not shown for clarity. (b) 2D coordination network of complex 2 viewed down from the $c$ axis and the intra-layer $\pi-\pi$ stacking interactions of complex 2 . (c) 2D coordination network of complex 2 viewed down from $c$ axis, the dihedral between bpe and the presentation of EAC, and a cartoon used to express the EAC visually. (d) The inter-layer $\mathrm{H}$-bonding $(\mathrm{O} 16-\mathrm{H} 16 \cdots \mathrm{O} 6,1.871 \AA$, 2.698

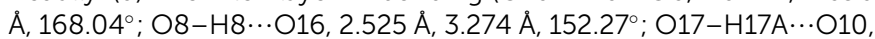
$2.044 \AA, 2.878 \AA, 166.40^{\circ}$ ).

limitation of bpe length, there is not enough space for nucleobase paired H-bonding formation, which makes the orientation of nucleobase of UMP in complex 2 separated from each other in an opposite manner relative to those of bpe (Fig. $3 \mathrm{~b}$ and $\mathrm{S} 9 \dagger$ ). The phosphate group can thus bridge $\mathrm{Cu}$ ions between adjacent chains (5.057(1) $)$, which results in a 2D coordination polymer. In the $2 \mathrm{D}$ sheet, there are strong $\pi-\pi$ stacking interactions (3.343 $\AA$ and $3.741 \AA$ ) between the pyrimidine bases of UMP and bpe, which induce aryl-aryl torsion of bpe. Thus, coordination and noncovalent interaction produced dihedral angle of the adjacent bpe linked to $\mathrm{Cu}$ (II) was $81.8^{\circ}$ (Fig. S10 $\dagger$ ); two pyridine rings of the bpe were $9.7^{\circ}$ ( $a b$ plane) and $7.1^{\circ}$ (vector direction) (Fig. 3c and $\mathrm{S} 11 \dagger$ ). This generates a new type of supramolecular chirality, called extended axial chirality (EAC). The configuration of bpe in complex 2 is $P$-EAC because the UMP ligands surround the axis in a clockwise manner. The chirality of the $2 \mathrm{D}$ layers can be delivered into the 3D architecture by three types of $\mathrm{H}$-bonding from phosphate oxygen atom with ribose hydroxyl

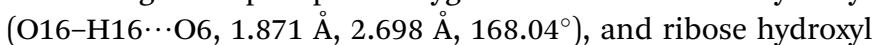
with coordination water (O8-H8 $\cdots \mathrm{O} 16,2.525 \AA$, $3.274 \AA$,

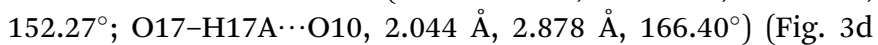
and $\mathrm{S} 12 \dagger)$.

\section{Circular dichroism (CD) spectroscopy}

According to the structural analysis, supramolecular helical chirality and the EAC appeared in complexes $\mathbf{1}$ and $\mathbf{2}$. In order to identify the new chirality, the aqueous solution and solid-state CD spectra were recorded. ${ }^{17,30}$ All the samples were phase pure, which was verified by single crystal by X-ray powder diffraction (XRPD) measurements (Fig. S13†).

The aqueous solution CD spectra (Fig. 4a) for UMP had two typical broad peaks centered near 250 and $280 \mathrm{~nm}$. Specifically,
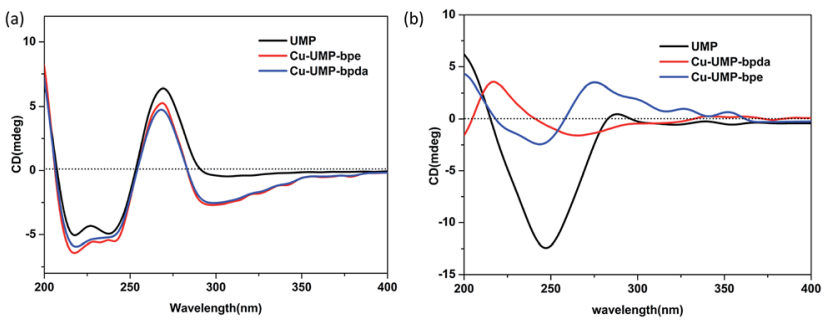

Fig. 4 (a) The CD spectra of the solution of UMP and its complexes. The spectrum was obtained by measuring a $0.25 \mathrm{mM}$ solution in a 1 $\mathrm{mm}$ cell. (b) The solid-state CD spectra of the UMP ligand and its complexes 1 and 2 ( $\mathrm{KCl}$ : [sample] $=200: 1)$.

the stronger and wider negative envelope near $247 \mathrm{~nm}$ corresponds to the intermolecular $\pi-\pi^{*}$ and $n-\pi^{*}$ transitions. The positive absorption near $285 \mathrm{~nm}$ for UMP relates to the intermolecular $\pi-\pi^{*}$ interaction between nucleotide bases, which indicates that the UMP is a D-ribonucleotide. ${ }^{31}$ Compared to the ligand, there was a new negative absorption at $300 \mathrm{~nm}$ in $\mathbf{1}$ and 2. Because the coordination of $\mathrm{Cu}(\mathrm{II})$ with UMP prevents the mutarotation of the ligand, making ligands keep the $\beta$-anomers in their complexes. ${ }^{\mathbf{1 6 , 1 7}}$

The solid-CD (Fig. 4b) for complex 1 was significantly different compared with UMP. A positive and new peak at $227 \mathrm{~nm}$ indicated that an additional chiral source was present, which was a result of the supramolecular helix changing the symmetry of electronic transition of UMP. ${ }^{16,17,32}$ The $227 \mathrm{~nm}$ CD signal transition is the excitation coupling of the $\pi-\pi^{*}$ transitions of the intra- and intermolecular uridine chromophores. On comparison, it was found that the solid-CD for complex 2 was similar to UMP, except for the weak positive acromions above $300 \mathrm{~nm}$, and this can be attributed to the EAC of bpe, which was caused by the $\pi-\pi^{*}$ transitions between bpe and pyrimidine of UMP; this can be confirmed by structure research. ${ }^{33}$

\section{Conclusion}

Two nucleotide coordination complexes Cu-UMP-bpda/bpe were synthesized and their different architectures were studied by X-ray single crystal diffraction analysis. A 1D doublebridged structure was obtained that was totally different from the previous structure of bpda and nucleotide complexes. The important aim of the crystallography study of Cu-UMP-bpda/ bpe is establishing a structural fundament to comprehensively understand the relative functional properties, such as chirality. Furthermore, the extended axial chirality (EAC) and supramolecular chirality were investigated in detail based on their crystal structure and aqueous solution and solid-state CD spectral analysis. The torsion of bpe leads to EAC and the 1D parallel double-bridged structure of bpda limits the rotation of aromatic rings, and hence no EAC appeared for 1 . Moreover, the large torsion of UMP leads to a supramolecular helix by H-bonding in 2. Our present study provides a profound understanding of the relationship between structure and chirality, and promises to provide another effective method for researching nucleotide self-assembly through changing the length of the auxiliary ligand. 


\section{Acknowledgements}

This study was financially supported by the National Natural Science Foundation of China (no. 21271026, 21471017).

\section{Notes and references}

1 B. Roy, A. Depaix, C. Périgaud and S. Peyrottes, Chem. Rev., 2016, 116, 7854.

2 M. Yamada and K. Abe, Polym. J., 2014, 46, 366.

3 L. Berti and G. A. Burley, Nat. Nanotechnol., 2008, 3, 81.

4 V. Allain, C. Bourgaux and P. Couvreur, Nucleic Acids Res., 2012, 40, 1891.

5 K. Sureka, P. H. Choi, M. Precit, M. Delince, D. A. Pensinger, T. N. Huynh, A. R. Jurado, Y. A. Goo, M. Sadilek, A. T. Iavarone, et al., Cell, 2014, 158, 1389.

6 V. A. Tverdislov, Biophysics, 2013, 58, 128.

7 K. Aoki and K. Murayama, Met. Ions Life Sci., 2012, 10, 43.

8 R. K. O. Sigel and H. Sigel, Acc. Chem. Res., 2010, 43(974), 9. 9 P. Zhou, R. Shi, J. F. Yao, C. F. Sheng and H. Li, Coord. Chem. Rev., 2015, 292, 107.

10 C.-Y. Zheng and H. Li, Inorg. Chem. Commun., 2013, 34, 30. 11 H. Sigel and R. Griesser, Chem. Soc. Rev., 2005, 34, 875.

12 M. Benedetti, G. Tamasi, R. Cini, L. G. Marzilli and G. Natile, Chem.-Eur. J., 2007, 13, 3131.

13 D. Maruyama, Y. Nishitani, T. Nonaka, A. Kita, T. A. Fukami, T. Mio, H. Yamada-Okabe, T. Yamada-Okabe and K. J. Miki, Biol. Chem., 2007, 282, 17221.

14 L. A. Herrero and A. J. Terron, Biol. Aspects Inorg. Chem., 2000, 5, 269.

15 M. Kato, A. K. Sah, T. Tanase and M. Mikuriya, Eur. J. Inorg. Chem., 2006, 2504.

16 P. Zhou, J. F. Yao, C. F. Sheng and H. Li, CrystEngComm, 2013, 15, 8430.

17 P. Zhou and H. Li, Dalton Trans., 2011, 40, 4834.

18 N. Chen, M. X. Li, P. Yang, X. He, M. Shao and S. R. Zhu, Cryst. Growth Des., 2013, 13, 2650.
19 M. Cattaneo, F. Fagalde and N. E. Katz, Inorg. Chem., 2006, 45, 6884.

20 W. S. Zou, Q. J. Shen, Y. Wang and W. J. Jin, Chem. Res. Chin. Univ., 2008, 24, 712.

21 A. J. Calahorro, E. S. Sebastián, A. Salinas-Castillo, J. M. Seco, C. Mendicute-Fierro, B. Fernández and A. RodríguezDiéguez, CrystEngComm, 2015, 17, 3659.

22 D. M. Ciurtin, Y. B. Dong, M. D. Smith, T. Barclay and H. C. Zur Loye, Inorg. Chem., 2001, 40, 2825.

23 J. B. Hou, G. Tang, J. N. Guo, Y. Liu, H. Zhang and Y. F. Zhao, Tetrahedron: Asymmetry, 2009, 20, 1301.

24 G. Sheldrick, Acta Crystallogr., Sect. A: Found. Crystallogr., 2008, 64, 112.

25 Q.-X. Zhou, W.-H. Lei, Y.-J. Hou, Y.-J. Chen, C. Li, B.-W. Zhang and X.-S. Wang, Dalton Trans., 2013, 42, 2786.

26 S. Brahma, S. K. A. Ikbal, S. Dey and S. P. Rath, Chem. Commun., 2012, 48, 4070.

27 W. Liu, H. Zhu, B. Zheng, S. Cheng, Y. Fu, W. Li, T. C. Lau and H. Liang, Nucleic Acids Res., 2012, 40, 4229.

28 P. Suvanvapee, J. Boonmak, F. Klongdee, C. Pakawatchai, B. Moubaraki, K. S. Murray and S. Youngme, Cryst. Growth Des., 2015, 15, 3804.

29 A. Meyer, G. Schnakenburg, R. Glaum and O. Schiemann, Inorg. Chem., 2015, 54, 8456.

30 P. Zhou, C. Wang, Q. M. Qiu, J. F. Yao, C. F. Sheng and H. Li, Dalton Trans., 2015, 44, 17810.

31 A. I. S. Holm, E. S. Worma, T. Chakraborty, B. R. Babu, J. Wengel, S. V. Hoffmann and S. B. Nielsen, J. Photochem. Photobiol., A, 2007, 187, 293.

32 G. Pescitelli, L. D. Bari and N. Berova, Chem. Soc. Rev., 2014, 43, 5211.

33 S. M. Quarrie, A. Blanc, N. J. Mosey, C. M. Crudden, R. P. Lemieux and M. P. Thompson, J. Am. Chem. Soc., 2008, 130, 14099. 